OPEN ACCESS

Edited by: Susan M. Rivera, University of California, Davis, United States

Reviewed by: Vanessa LoBue,

Rutgers, The State University of New Jersey, United States Vrinda Kalia,

Miami University, United States

*Correspondence:

Rista C. Plate

rplate@wisc.edu

Specialty section: This article was submitted to Developmental Psychology, a section of the journal Frontiers in Psychology

Received: 09 November 2018 Accepted: 13 February 2019 Published: 05 March 2019

Citation:

Plate RC, Bloomberg Z, Bolt DM, Bechner AM, Roeber BJ and Pollak SD (2019) Abused Children Experience High Anger Exposure. Front. Psychol. 10:440. doi: 10.3389/fpsyg.2019.00440

\section{Abused Children Experience High Anger Exposure}

\author{
Rista C. Plate ${ }^{1,2 *}$, Zachary Bloomberg², Daniel M. Bolt ${ }^{2}$, Anna M. Bechner ${ }^{2}$, \\ Barbara J. Roeber ${ }^{2}$ and Seth D. Pollak ${ }^{1,2}$ \\ ${ }^{1}$ Department of Psychology, University of Wisconsin-Madison, Madison, WI, United States, ${ }^{2}$ Waisman Center, University \\ of Wisconsin-Madison, Madison, WI, United States
}

Childhood maltreatment is a critical problem in the United States. Much attention has been paid to the negative outcomes suffered by victims of abuse. Less attention has been devoted to understanding the emotional environments of maltreated children. One assumption, which has stood without empirical test, is that abused children encounter a high degree of anger in their home environments. Anger exposure is thought to be a source of stress for children in abusive environments and a potential link between the experience of abuse and the development of health and behavioral problems. We tested this notion by assessing data on over 1,000 parents and guardians of 3- to 17-year-old children who were participants in child development studies. Abuse was measured via records from Child Protective Services regarding substantiated and unsubstantiated claims of abuse as well as parent/guardian report. We compared self-reported experiences of anger from parents/guardians of children who have experienced abuse with those who have not. We found support for the claim that caregivers of abused children experience and express high levels of anger. Better characterization of the emotional environments in which abused children develop is critical for understanding how and why abuse affects children and has important implications for informing interventions.

Keywords: child maltreatment, anger, physical abuse, parents, children

\section{INTRODUCTION}

Child maltreatment is a significant public health concern in the United States. In 2016, 676,000 children were found to be substantiated victims of abuse or neglect (U.S. Department of Health \& Human Services et al., 2018). Despite attention and efforts to reduce childhood abuse (Reynolds and Robertson, 2003), the number of victims continues to increase. Moreover, the instance of childhood abuse is likely higher than recorded, given that many cases are not substantiated or reported.

Victims of abuse are at risk for myriad poor physical and mental health outcomes (McLaughlin, 2016). For several decades, anger in the home environment has played a central role in theories about how and why abused children develop health and behavioral problems. Given that abuse is hostile or aggressive by nature, the assumption that abusive caregivers express - and that abused children witness - a lot of anger is reasonable. Many of the major theoretical accounts about the etiology of problems linked to abuse take high levels of anger exposure as an a priori assumption. For example, empirical studies drawn from a variety of foci such as social learning (Larrance and Twentyman, 1983; Bousha and Twentyman, 1984), perceptual learning (Pollak et al., 1997, 2001), 
emotion socialization (Perlman et al., 2008), attachment (Dozier et al., 2008), trauma (Briggs-Gowan et al., 2012, 2019), and gene $\times$ environment effects (Jaffee and Price, 2007) imply that their results are due, in part, to abused children's exposure to high levels of anger. For example, that physically abused children discriminate between emotions differently than neglected or nonmaltreated children is thought to result from exposure to an environment rich in emotional threat cues (Pollak et al., 2000). Even accounts that focus directly on specific aspects of abusive parenting - such as deficits in self-control and problem-solving skills - had to assume high levels of familial anger (Azar et al., 1984; Cowell et al., 2015). In addition, anger expression has been correlated with child abuse potential (Rodriguez and Green, 1997; Rodriguez, 2010).

Here, we sought to answer one fundamental question: Is there evidence to support the claim that children who are developing in abusive families are exposed to more frequent and/or more severe expressions of anger? To address this question, we collected data about anger expression from parents and guardians whose children participated in a variety of child development studies.

\section{MATERIALS AND METHODS}

\section{Participants}

Participants were 1019 parents and guardians of children who visited our laboratory to participate in one of 39 child development studies from 2000 to 2017 (see Supplementary Materials for participant recruitment and exclusions). Parents and children gave informed, written consent for the study in which they participated (children under age 11 years old provided informed, verbal assent). Participants were mothers (87\%), fathers (11\%), and legal guardians (or unreported, 2\%). Parents and guardians were between 23 and 73 years of age $(M=41.12, S D=7.39,79$ did not report age $)$ and their children were between 3 and 17 years of age $(M=9.69, S D=2.87,47 \%$ female) when the data were collected.

\section{Determination of Abuse Status}

We defined abuse as substantiated reports with Child Protective Services (CPS) and/or scores greater than or equal to 20 on the physical assault portion of a commonly used scale to assess childhood maltreatment (Conflict Tactics Scale Parent-Child Version; CTSPC; Straus et al., 1998; see Supplementary Materials for sample items). Parents/guardians of 106 children were included in the Abuse group based on high CTSPC and/or CPS reports.

We included parents/guardians in the No Abuse group if they scored less than 10 on the CTSPC and had no CPS records. Two hundred six parents/guardians had unsubstantiated or on-going reports of child maltreatment with the county, notations of "concern" without sufficient evidence from CPS, elevated CTSPC scores but fell short of the threshold (i.e., scores that were $>10$ but $<20$ ), and/or another child with substantiated maltreatment. We decided to include these participants in the Abuse group. Based on our experience and the suspected underreporting of child abuse, we reasoned these are cases where experts have good reason to be concerned about child welfare, but not yet sufficient evidence to trigger social services involvement. Note that if this assumption is incorrect, we have merely added noise to our data, dampening the effect of interest. The final groups of interest included 312 parents/guardians of children who have likely experienced abuse (Abuse group) and 707 parents/guardians of children who have no indications of having experienced abuse (No Abuse group).

\section{Measure}

The State-Trait Anger Expression Inventory Revised Second Edition (STAXI-2; Spielberger and Sydeman, 1994) was used to measure participants' experience, expression, and control of anger. Fifty-seven items in six subscales and one index were rated on a 4-point forced-choice response scale (see Supplementary Materials for subscale, reliability, and validity information). The 32-item Anger Expression Index (AX-Index) provides an overall index of anger expression, with scores ranging from 0 to 96.

\section{RESULTS}

\section{Comparison of Group Demographics}

The Abuse and No Abuse groups did not differ in age of the child participating in the study, the child's sex, or proportion of mothers versus not mothers (i.e., fathers, legal guardians; means and comparisons presented in Table 1). Parents/guardians of the Abuse group were younger than those in the No Abuse group and had lower SES than those in the No Abuse group (Hollingshead Four-Factor Index of Socioeconomic Status; Hollingshead, 1975; 234 participants did not report SES).

\section{Do Abused Children Experience High Anger Exposure?}

We expected a linear relationship between group and anger exposure, therefore we regressed AX-Index on group (Abuse $=0.5$, No Abuse $=-0.5$ ). Parents/guardians of abused children had higher anger expression scores compared to parents/guardians of not abused children $[b=4.462$, $\left.F(1,1017)=54.73, p<0.001, R^{2}=0.05\right]$. We separately compared children with unsubstantiated reports of child abuse against the No Abuse group. Parents/guardians of children with unsubstantiated abuse also reported higher anger expression compared to parents/guardians of not abused children $\left[b=2.948, F(1,911)=18.21, p<0.001, R^{2}=0.02\right]$; however, caregivers of children with unsubstantiated abuse reported lower anger expression than those of abused children $\left[b=4.45, F(1,310)=15.88, p<0.001, R^{2}=0.05\right]$. Therefore, there may be meaningful variation based on amount of abuse. Consistent with this idea CTSPC scores were correlated with anger expression; parents/guardians who reported higher rates of child abuse reported greater anger expression, $r(1005)=0.191$, $p<0.001,95 \%$ CI $(0.131,0.250)$.

Because the groups differed by parent/guardian age and SES, we ran a second model including these variables to ensure that the effect was not being driven by alternative factors. We regressed 
TABLE 1 | Participant and child demographics by group.

\begin{tabular}{lccc}
\hline & Abuse & No Abuse & Comparison \\
\hline Child age [Mean (SD)] & $9.54(2.77)$ & $9.76(2.92)$ & $b=-0.221, F(1,1017)=1.286$, \\
& & & $p=0.257, R^{2}=0.001$ \\
Child sex (N) & 145 female, 167 male & 334 female, 373 male & $X^{2}(1)=0.025, p=0.874$ \\
Respondent (N) & 266 mothers, 46 not mothers & 619 mothers, 88 not mothers & $X^{2}(1)=0.809, p=0.369$ \\
Parent/guardian age [Mean (SD)] & $39.45(8.02)$ & $41.81(7.01)$ & $b=-2.359, F(1,938)=20.17$, \\
& & & $p<0.001, R^{2}=0.021$ \\
SES [Mean (SD)] & $40.45(15.6)$ & $51.74(11.35)$ & $b=-11.284, F(1,783)=126.2$, \\
Child race (N) & & & $p<0.001, R^{2}=0.139$ \\
Black & 101 & 66 & 502 \\
White & 138 & 39 & 9 \\
Asian & 14 & 51 & \\
Hispanic & 10 & 39 & \\
Multi-racial & 33 & 16 & \\
Other/not-reported & & & \\
\hline
\end{tabular}

anger expression on group, respondent age (mean-centered), SES (mean-centered), and their interaction terms (Note: 251 observations did not include respondent age or SES and were therefore excluded from the analysis including covariates). Controlling for parent/guardian age and SES, the effect of group on anger expression maintained significance, $b=3.382$, $t(760)=4.292, p<0.001, \Delta R^{2}=0.023$. Additionally, there was a significant effect of SES; as SES increased, reported anger expression decreased, $b=-0.063, t(760)=-2.415, p=0.016$, $\Delta R^{2}=0.007$. However, the effect of SES explained less variance in the model than the effect of group. No other effects or interactions in the model were significant $(p s>0.580)$. While we were primarily interested in overall anger expression, subscale comparisons are presented in Table 2.

\section{DISCUSSION}

We set out to test whether abused children encounter more expressed anger in their family environments, and we found that parents/guardians of abused children do indeed report greater anger expression than those of not abused children. This greater amount of anger spans state and trait anger, and parents/guardians of abused children report less ability to control their expression of anger.
While we did not initially predict a relation between anger expression and SES; we discovered this relation by including SES in the model. However, the relation is not entirely surprising. Individuals with fewer financial and educational resources likely encounter greater barriers than those with more resources. Such increased stress could influence the amount of anger an individual experiences, as well as the individual's ability to control its expression. Further, this is not the first investigation to note concurrence between abuse and income. Both physically abused children and children from very low-income families have shown neurocognitive delays and behavioral problems (Hanson et al., 2013). Alternatively, families with higher levels of education may pay greater attention to societal expectations, and therefore may simply be better at tempering how they complete questionnaires in the laboratory environment.

\section{Implications of Exposure to Anger}

Exposure to high levels of hostility in the home environment may contribute to downstream effects of important mechanisms linking maltreatment to adverse outcomes. For example, exposure to consistent anger, signaling a threatening environment, may influence children's diurnal cortisol rhythms, which moderate the relation between abuse and aggressive

TABLE 2 | Sample means (standard deviations) for STAXI measures and group comparisons.

\begin{tabular}{|c|c|c|c|c|}
\hline Measure & Description & Abuse Mean (SD) & No Abuse Mean (SD) & Comparison \\
\hline AX_Index & Anger expression & $53.47(9.57)$ & $49.01(8.55)$ & $F(1,1017)=54.73, p<0.001, R^{2}=0.05$ \\
\hline S_Ang & State anger & $47.49(8.06)$ & $45.01(3.51)$ & $F(1,1012)=46.67, p<0.001, R^{2}=0.044$ \\
\hline T_Ang & Trait anger & $46.72(10.24)$ & $43.09(7.71)$ & $F(1,1017)=38.74, p<0.001, R^{2}=0.038$ \\
\hline$A X-1$ & Anger expression-inward & $49.91(10.64)$ & $47.04(9.29)$ & $F(1,989)=18.40, p<0.001, R^{2}=0.018$ \\
\hline$A X-O$ & Anger expression-outward & $52.31(11.29)$ & $48.24(9.1)$ & $F(1,1016)=37.09, p<0.001, R^{2}=0.035$ \\
\hline$A C-1$ & Anger control-inward & $46.67(9.38)$ & $49.49(9)$ & $F(1,1017)=20.69, p<0.001, R^{2}=0.020$ \\
\hline $\mathrm{AC}-\mathrm{O}$ & Anger control-outward & $45.8(10.76)$ & $48.98(10.13)$ & $F(1,1016)=20.52, p<0.001, R^{2}=0.020$ \\
\hline
\end{tabular}

All effects maintained statistical significance (ps $\leq 0.01)$ when respondent age and SES were included in the model. 
behavior (Bernard et al., 2015). Additionally, the amount of anger a child observes influences how children form emotion category representations, which in turn influence the judgments that people make about others (Etcoff and Magee, 1992; Campanella et al., 2002; Plate et al., 2018). Consistent with this idea, abused children perceptually discriminate emotional faces differently from non-abused children (Pollak and Kistler, 2002). Interpreting emotions is a key component of social competence, and failure to master this critical skill could have damaging effects on children's social development.

Another implication of greater anger exposure might be children's observational learning. Research has long shown that a primary source of children's learning occurs through observations of others (e.g., Bandura and Walters, 1977). When one of a child's primary models expresses great amounts of anger, the child may adopt those standards of expression. Further, these data suggest that parents/guardians of maltreated children demonstrate less ability to control their anger (as evidenced by differences on anger control subscales), therefore limiting the observational opportunities for these children to learn emotion regulation, a skill often reduced in maltreated children (Heleniak et al., 2016).

\section{Limitations}

One limitation is that anger expression was determined via self-report alone. It is unlikely that parents exaggerated their anger expression. However, it is possible that respondents underestimated or inaccurately reported anger expression. This could happen intentionally, as respondents modulate their responses according to suspected norms, or because individuals may not have insight into their own emotional lives. Additionally, because CPS reports vary greatly in the level of detail available, there were some cases where we could not ascertain if the respondent was deemed responsible for instances of substantiated abuse. This uncertainty potentially works against the effects we were testing, but should still be considered in interpreting the results. Nevertheless, what parents are choosing to reveal suggests that abused children not only experience direct acts of aggression, but abused children likely develop within hostile family contexts.

Another limitation is that many children experience more than one type of maltreatment. Here, we focused on abuse, specifically physical abuse as measured by the CTSPC. However, there is a high co-occurrence amongst different types of maltreatment (Vachon et al., 2015), and certain types of abuse (i.e., emotional abuse) can be particularly difficult to detect or substantiate. Additionally, the effect size for the relation between abuse and anger exposure is small. It is likely that myriad other factors also contribute to the complex experiences of children living in abusive environments.

\section{CONCLUSION}

We addressed one key question, namely, whether abused children encounter a lot of anger in their home environment. While seemingly simple, this empirical question has been taken as an assumption in the literature. Here we provide evidence that abused children are exposed to greater amounts of caregiver anger than children who have not been abused. Questions remain regarding the implications of this finding for mechanisms linking maltreatment to adverse outcomes. Given the persistent frequency of childhood maltreatment, as well as the detrimental and expansive consequences, these questions remain critical to address in order to advance scientific understanding and policy to protect vulnerable youth.

\section{DATA AVAILABILITY}

The de-identified dataset and analysis script are available at: https://osf.io/35xzt/.

\section{ETHICS STATEMENT}

The protocol was approved by the University of Wisconsin Institutional Review Board. Written informed consent was obtained from all adult participants and from the parents/legal guardians of all non-adult participants.

\section{AUTHOR CONTRIBUTIONS}

$\mathrm{ZB}$ and SP conceptualized the research question. RP, DB, $A B$, and $B R$ assisted with data preparation and analysis. RP drafted the manuscript. All authors provided the critical revisions.

\section{FUNDING}

This research was supported by the National Institute of Mental Health through grant R01MH61285 to SP and in part by a core grant to the Waisman Center from the National Institute of Child Health and Human Development (U54 HD090256). RP was supported by a National Science Foundation Graduate Research Fellowship (DGE-1256259) and the Richard L. and Jeanette A. Hoffman Wisconsin Distinguished Graduate Fellowship.

\section{ACKNOWLEDGMENTS}

We thank the families who participated in this study and the research assistants who helped to conduct the research.

\section{SUPPLEMENTARY MATERIAL}

The Supplementary Material for this article can be found online at: https://www.frontiersin.org/articles/10.3389/fpsyg. 2019.00440/full\#supplementary-material 


\section{REFERENCES}

Azar, S. T., Robinson, D. R., Hekimian, E., and Twentyman, C. T. (1984). Unrealistic expectations and problem-solving ability in maltreating and comparison mothers. J. Consult. Clin. Psychol. 52:687. doi: 10.1037/0022-006X. 52.4.687

Bandura, A., and Walters, R. H. (1977). Social Learning Theory, Vol. 1. Englewood Cliffs, NJ: Prentice-hall.

Bernard, K., Zwerling, J., and Dozier, M. (2015). Effects of early adversity on young children's diurnal cortisol rhythms and externalizing behavior. Dev. Psychobiol. 57, 935-947. doi: 10.1002/dev.21324

Bousha, D. M., and Twentyman, C. T. (1984). Mother-child interactional style in abuse, neglect, and control groups: naturalistic observations in the home. J. Abnor. Psychol. 93:106. doi: 10.1037/0021-843X.93.1.106

Briggs-Gowan, M. J., Carter, A. S., and Ford, J. D. (2012). Parsing the effects violence exposure in early childhood: modeling developmental pathways. J. Pediatr. Psychol. 37:22. doi: 10.1093/jpepsy/jsr063

Briggs-Gowan, M. J., Estabrook, R., Grasso, D., Henry, D., Burns, J., McCarthy, K. J., et al. (2019). Parsing dimensions of family violence exposure in early childhood: shared and specific contributions to emergent psychopathology and impairment. Child Abuse Negl. 87, 100-111. doi: 10.1016/j.chiabu.2018.06.006

Campanella, S., Quinet, P., Bruyer, R., Crommelinck, M., and Guerit, J.-M. (2002). Categorical perception of happiness and fear facial expressions: an ERP study. J. Cognit. Neurosci. 14, 210-227. doi: 10.1162/089892902317236858

Cowell, R. A., Cicchetti, D., Rogosch, F. A., and Toth, S. L. (2015). Childhood maltreatment and its effect on neurocognitive functioning: timing and chronicity matter. Dev. Psychopathol. 27, 521-533. doi: 10.1017/ S0954579415000139

Dozier, M., Stovall-McClough, K. C., and Albus, K. E. (2008). “Attachment and psychopathology in adulthood," in Handbook of Attachment: Theory, Research, and Clinical Applications, eds J. Cassidy and P. R. Shaver (New York, NY: Guilford Press), 718-744.

Etcoff, N. L., and Magee, J. J. (1992). Categorical perception of facial expressions. Cognition 44, 227-240. doi: 10.1016/0010-0277(92)90002-Y

Hanson, J. L., Hair, N., Shen, D. G., Shi, F., Gilmore, J. H., Wolfe, B. L., et al. (2013). Family poverty affects the rate of human infant brain growth. PLoS One 8:e80954. doi: 10.1371/journal.pone.0080954

Heleniak, C., Jenness, J. L., Vander Stoep, A., McCauley, E., and McLaughlin, K. A. (2016). Childhood maltreatment exposure and disruptions in emotion regulation: a transdiagnostic pathway to adolescent internalizing and externalizing psychopathology. Cognit. Ther. Res. 40, 394-415. doi: 10.1007/ s10608-015-9735-z

Hollingshead, A. B. (1975). Four Factor Index of Social Status. New Haven, CT: Yale University.

Jaffee, S. R., and Price, T. S. (2007). Gene-environment correlations: a review of the evidence and implications for prevention of mental illness. Mol. Psychiatry 12:432. doi: 10.1038/sj.mp.4001950

Larrance, D. T., and Twentyman, C. T. (1983). Maternal attributions and child abuse. J. Abnor. Psychol. 92:449. doi: 10.1037/0021-843X.92.4.449

McLaughlin, K. (2016). Future directions in childhood adversity and youth psychopathology. J. Clin. Child Adolesc. Psychol. 45, 361-382. doi: 10.1080/ 15374416.2015.1110823

Perlman, S. B., Camras, L. A., and Pelphrey, K. A. (2008). Physiology and functioning: parents' vagal tone, emotion socialization, and children's emotion knowledge. J. Exp. Child Psychol. 100, 308-315. doi: 10.1016/j.jecp.2008. 03.007

Plate, R. C., Wood, A., Woodard, K., and Pollak, S. D. (2018). Probabilistic learning of emotion categories. J. Exp. Psychol. Gen. doi: 10.1037/xge0000529 [Epub ahead of print].

Pollak, S. D., Cicchetti, D., Hornung, K., and Reed, A. (2000). Recognizing emotion in faces: developmental effects of child abuse and neglect. Dev. Psychol. 36, 679-688. doi: 10.1037//0012-1649.36.5.679

Pollak, S. D., Cicchetti, D., Klorman, R., and Brumaghim, J. (1997). Cognitive brain event-related potentials and emotion processing in maltreated children. Child Dev. 68, 773-787. doi: 10.1111/j.1467-8624.1997.tb01961.x

Pollak, S. D., and Kistler, D. J. (2002). Early experience is associated with the development of categorical representations for facial expressions of emotion. Proc. Natl. Acad. Sci. U.S.A. 99, 9072-9076. doi: 10.1073/pnas.142165999

Pollak, S. D., Klorman, R., Thatcher, J. E., and Cicchetti, D. (2001). P3b reflects maltreated children's reactions to facial displays of emotion. Psychophysiology 38, 267-274.

Reynolds, A. J., and Robertson, D. L. (2003). School-based early intervention and later child maltreatment in the Chicago longitudinal study. Child Dev. 74, 3-26. doi: 10.1111/1467-8624.00518

Rodriguez, C. M. (2010). Personal contextual characteristics and cognitions: predicting child abuse potential and disciplinary style. J. Interpers. Violence 25, 315-335. doi: 10.1177/0886260509334391

Rodriguez, C. M., and Green, A. J. (1997). Parenting stress and anger expression as predictors of child abuse potential. Child Abuse Negl. 21, 367-377. doi: 10.1016/S0145-2134(96)00177-9

Spielberger, C. D., and Sydeman, S. J. (1994). "State-trait anxiety inventory and state-trait anger expression inventory," in The Use of Psychological Testing for Treatment Planning and Outcome Assessment, ed. M. E. Maruish (Hillsdale, NJ: Lawrence Erlbaum Associates), 292-321.

Straus, M. A., Hamby, S. L., Finkelhor, D., Moore, D. W., and Runyan, D. (1998). Identification of child maltreatment with the parent-child conflict tactics scales: development and psychometric data for a national sample of American parents. Child Abuse Negl. 22, 249-270. doi: 10.1016/S0145-2134(97)00174-9

U.S. Department of Health \& Human Services, Administration for Children and Families, Administration on Children, Youth and Families, Children's Bureau. (2018). Child Maltreatment 2016. Available at: https://www.acf.hhs.gov/cb/ research-data-technology/statistics-research/child-maltreatment

Vachon, D. D., Krueger, R. F., Rogosch, F. A., and Cicchetti, D. (2015). Assessment of the harmful psychiatric and behavioral effects of different forms of child maltreatment. JAMA Psychiatry 72, 1135-1142. doi: 10.1001/jamapsychiatry. 2015.1792

Conflict of Interest Statement: The authors declare that the research was conducted in the absence of any commercial or financial relationships that could be construed as a potential conflict of interest.

Copyright (C) 2019 Plate, Bloomberg, Bolt, Bechner, Roeber and Pollak. This is an open-access article distributed under the terms of the Creative Commons Attribution License (CC BY). The use, distribution or reproduction in other forums is permitted, provided the original author(s) and the copyright owner(s) are credited and that the original publication in this journal is cited, in accordance with accepted academic practice. No use, distribution or reproduction is permitted which does not comply with these terms. 